\title{
THIN FILM COMPOSITES OF NANOCRYSTALLINE DIAMOND \\ PARTICLES AND DIAMOND-LIKE CARBON: STRUCTURAL, ELECTROCHEMICAL AND BIOLOGICAL PROPERTIES
}

\author{
C. A. Nunes \\ Laboratory of Biomedical Nanotechnology, Universidade do Vale do Paraíba (Univap), \\ Av. Shishima Hifumi 2911, São José dos Campos, SP, Brazil \\ B. C. Ramos \\ Laboratory of Biomedical Nanotechnology, Universidade do Vale do Paraíba (Univap), \\ Av. Shishima Hifumi 2911, São José dos Campos, SP, Brazil

\section{F. Stein} \\ Laboratory of Biomedical Nanotechnology, Universidade do Vale do Paraíba (Univap), \\ Av. Shishima Hifumi 2911, São José dos Campos, SP, Brazil
}

\section{E. C. Almeida}

Departamento de Ciências Exatas e Tecnológicas (DCET), Universidade Estadual de Santa Cruz (UESC), Rodovia Ilheus- Itabuna, Km 16 (BA 415), Ilhéus, BA, Brazil

\section{N. S. Da-Silva}

Laboratório de Dinâmica de Compartimentos Celulares, Universidade do Vale do Paraíba (Univap), Av. Shishima Hifumi 2911, São José dos Campos, SP, Brazil

\section{P. Soares}

Laboratório de Dinâmica de Compartimentos Celulares, Universidade do Vale do Paraíba (Univap), Av. Shishima Hifumi 2911, São José dos Campos, SP, Brazil

\section{J. Trava-Airoldi}

Laboratório Associado de Sensores e Materiais (LAS), Instituto Nacional de Pesquisas Espaciais (INPE), Av. dos Astronautas 1758, São José dos Campos,SP,Brazil

\author{
A. O. Lobo \\ Laboratory of Biomedical Nanotechnology, Universidade do Vale do Paraíba (Univap), \\ Av. Shishima Hifumi 2911, São José dos Campos, SP, Brazil \\ F. R. Marciano \\ Laboratory of Biomedical Nanotechnology, Universidade do Vale do Paraíba (Univap), \\ Av. Shishima Hifumi 2911, São José dos Campos, SP, Brazil \\ femarciano@uol.com.br
}

\begin{abstract}
Diamond-like Carbon (DLC) films have been the focus of extensive research in recent years due to their potential application as surface coatings. In this paper, we report the main results obtained in our laboratories from the production and characterization of nanocrystalline diamond particles (NCD) incorporated in DLC films for biomedical applications. The films were growth on 316L stainless steel substrates from a dispersion of NCD nanoparticles in hexane using plasma enhanced chemical vapor deposition. Raman
\end{abstract}


scattering spectroscopy was used to study the atomic arrangements of the film, and atomic force microscopy, the roughness of the film. The investigation of NCD-DLC electrochemical corrosion behavior was performed using potentiodynamic method. Cell viability was evaluated with L-929 mouse fibroblast cells using 2-(4,5-dimethyl-2thiazolyl)-3,5-diphenyl-2H-tetrazolium bromide (MTT) in vitro assay. The NCD particles increased the structural diamond-like domains and surface roughness, which improved DLC and stainless steel electrochemical corrosion resistance and prevented aggressive ions from attacking metallic surfaces. Those NCD particles also increased the DLC cell viability, maximizing the potential use of NCD-DLC films in biomedical applications.

Keywords: diamond-like carbon, crystalline diamond nanoparticles, hexane, biomedical applications

\section{Introduction}

Diamond-like carbon (DLC) films have been actively studied over the last decade in the field of materials engineering. Consisting of dense amorphous carbon or hydrocarbon, the mechanical properties of DLC fall between those of graphite and diamond, which means that these films have low friction coefficient and high hardness (Robertson, 2002; Donnet et al., 1999; Tsai et al., 2008). Due to their mechanical, electrical, optical, and chemical properties, the use of DLC coatings in mechanical and electrical fields has increased with recent applications in food, beverage, and medical sectors (Donnet et al., 1999;Schiffmann, 2004; Suzuki and Kodama, 2009; Wang et al., 2009).

Metal ions incorporated into solid films in a controlled way are very important for academic research and industrial applications (Schmid, 1992; Wang et al., 1988). Metal ion-doped solid films can acquire different properties that combine the properties of the metal ion particles, especially nanoparticles, and the bulk of the host material (Shirakura et al, 2006; Ohno et al., 1997; Matsumoto et al, 1981; Tanaka et al, 1996; Takahara et al., 2001). In the case of DLC films, the main reported problem in their production is the difficulty of dispersing particles homogeneously in the DLC matrix (Schiffmann et al., 1999; Hussain et al., 2006).

In 1997, Zarrabian et al. observed for the first time the formation of cubic crystalline diamond grains in an amorphous matrix using electron cyclotron resonance plasma at low pressure with radio frequency power applied to the substrate. According to Lian et al., 2002, the properties of DLC films can be significantly enhanced by the presence of nanocrystalline diamond (NCD). They also reported the characterization of NCD in pure and Ru-doped DLC films. Later, Zhou et al., 2003, prepared composite films consisting of NCD embedded in an amorphous carbon (a-C) matrix using a prolonged bias assisted hot filament chemical vapor deposition conventionally used for diamond nucleation only for a short time. The nanocomposite with the highest nanodiamond density and average crystalline size of $\sim 6 \mathrm{~nm}$ was obtained for $1 \% \mathrm{CH}_{4}$. The increase of the $\mathrm{CH}_{4}$ concentration resulted in an increase of the nanocrystalline diamond size, but a reduction of the nanodiamond particle density and the diamond volume fraction in the composite. Hsieh et al., 2004, deposited NCD embedded in a-C/N films at a substrate temperature of $25^{\circ} \mathrm{C}$ in a nitrogen atmosphere using filtered cathodic arc plasma. According to them, NCD clusters can be nucleated to a size of $2-5 \mathrm{~nm}$ with substrate temperature of $25^{\circ} \mathrm{C}$ to enhance the mechanical properties of the a-C/N film. Sakudo et al., 2008, developed a method to deposit a DLC layer embedded with nanodiamond particles. To make both DLC and diamond coexist on a same substrate, they developed a method to form diamond at temperatures below $500 \mathrm{~K}$, because at a higher temperature DLC is easily crystallized and changed to graphite. Their coating had higher hardness than DLC and very low friction comparable to DLC.

A new technique developed in our laboratory permits the deposit of DLC films from hexane (Marciano et al., 2009). Using this technique, it is possible to deposit films from a dispersion of different kind of nanoparticles in hexane to create different kind of DLC films for different applications. In this paper, we show the main results obtained in our laboratories from the production and characterization of crystalline diamond nanoparticleincorporated DLC films for biomedical applications, which includes the evaluation of cellular behavior when in direct contact with this new biomaterial.

\section{Experimental procedures}

The 316L stainless steel (SS) substrates $\left(1 \times 1 \mathrm{~cm}^{2}\right)$ were mechanically polished to a mirror-like finished surface. All the substrates were cleaned ultrasonically in an acetone bath for $15 \mathrm{~min}$ and then dried in a nitrogen atmosphere. The clean samples were mounted on a water-cooled $4.8 \mathrm{~cm}$ diameter cathode powered by a directly pulsed current plasma enhanced chemical vapor deposition power supply, with variable pulse voltage from 0 to $1000 \mathrm{~V}$. 
In the plasma chamber (vacuum base pressure of $1.3 \mathrm{mPa}$ ), the substrates were additionally cleaned by argon discharge with $20 \mathrm{sccm}$ gas flow at $10.7 \mathrm{~Pa}$ working pressure and a discharge voltage of $-500 \mathrm{~V}$ for 20 min prior to deposition. To enhance the adhesion of DLC film to the substrate, carbonitriding was performed before DLC deposition. The carbonitriding was carried out mixing nitrogen, hydrogen, and methane gases in the proportion 12:3:1, respectively. The total flow was kept in $100 \mathrm{sccm}$ at $10.7 \mathrm{~Pa}$ for $2 \mathrm{~h}$ and a discharge voltage of $-560 \mathrm{~V}$.

The DLC films started to be deposited using methane as the powered gas to a thickness of around $1.0 \mu \mathrm{m}(20$ sccm gas flows at $10.7 \mathrm{~Pa}$ for $2 \mathrm{~h}$ and a discharge voltage of $-700 \mathrm{~V}$ ). After the DLC, deposition continues using hexane as the powered gas to a thickness of around $1.5 \mu \mathrm{m}$ (at $10.7 \mathrm{~Pa}$ for $1 \mathrm{~h}$ and a discharge voltage of -700 $\mathrm{V})$.

To produce NCD-DLC films, NCD particles of different average sizes $(4 \mathrm{~nm}, 250 \mathrm{~nm}$, and $500 \mathrm{~nm})$ were ultrasonically dispersed in different concentration $(0.1,0.3$, and $0.5 \mathrm{~g} / \mathrm{L})$ of hexane dispersion for 10 minutes. These NCD dispersions replaced the pure hexane during the DLC deposition to produce NCD-DLC films.

The atomic arrangement of the films was analyzed using Raman scattering spectroscopy (Renishaw 2000 system) with an $\mathrm{Ar}^{+}$-ion laser $(\lambda=514 \mathrm{~nm})$ in backscattering geometry. The laser power on the sample was $\sim 0.6$ $\mathrm{mW}$. The diameter of the laser spot was $2.5 \mu \mathrm{m}$. The Raman shift was calibrated with respect to the diamond peak at $1332.0 \mathrm{~cm}^{-1}$. All measurements were carried out in air at room temperature. The slopes of the photoluminescence background (PLB) in visible Raman spectra were used to estimate the hydrogen content in the films, following the methodology described by Casiraghi et al. (2005a and 2005b).

The film roughness value was characterized by a Wyko NT1100 optical profiler.

The electrochemical tests were performed using a conventional three-electrode electrochemical cell. In this cell, the reference electrode was a saturated $\mathrm{Ag} / \mathrm{AgCl}$ electrode, the counter electrode was a platinum wire, and the working electrodes were the stainless steel, DLC, and NCD-DLC films. The working electrode exposed area was $3.14 \mathrm{~cm}^{2}$. The electrolyte solution was a $0.5 \mathrm{~mol} / \mathrm{L}$ sodium chloride $(\mathrm{NaCl})$ aqueous solution, $\mathrm{pH} 5.8$, which was not stirred and was naturally aerated. Potentiodynamic tests were carried out by polarization of samples in the anodic direction, from -2.0 to $+2.0 \mathrm{~V}$, just after exposure to the electrolyte solution. The potential sweep rate was $1 \mathrm{mV} / \mathrm{s}$. The impedance measurements were also done in a $0.5 \mathrm{~mol} / \mathrm{L} \mathrm{NaCl}$ aqueous solution, $\mathrm{pH}$ 5.8. The electrochemical impedance spectra (EIS) were obtained over the frequency range $100 \mathrm{kHz}-10 \mathrm{mHz}$, at open circuit potential, with an $\mathrm{AC}$ excitation of $10 \mathrm{mV}$. All experiments were performed at room temperature.

Mouse fibroblast cells (L-929) were provided by the Cell Line Bank of Rio de Janeiro/Brazil (CR019). The cells were maintained as sub-confluent monolayers in minimum essential medium (MEM) with 1.5mM L-glutamine adjusted to contain $2.2 \mathrm{~g} / \mathrm{L}$ sodium bicarbonate $85 \%$, fetal bovine serum (FBS) $15 \%$ (Gibco, BRL), $100 \mathrm{units} / \mathrm{mL}$ penicillin-streptomycin (Sigma), and $25 \mu \mathrm{g} / \mathrm{mL}$ 1-ascorbic acid (Sigma). The incubation occurred in a $\mathrm{CO}_{2}(5 \%)$ atmosphere at $37^{\circ} \mathrm{C}$.

The cytotoxicity assay was evaluated according to ISO 10993-5 "Biological evaluation of medical devices - Test for cytotoxicity: in vitro methods" (or EN 30993-5), using direct contact. The proliferative activity of cultured cells was determined with MTT colorimetric assay, as described by Mosmannet al. (1983). Latex fragments were used as positive control. To prove the non-toxic nature, fragments of filter paper were used as negative control. The dimensions of these fragments were the same as the substrates with DLC and NCD-DLC films. All the samples were sterilized in humid vapor $\left(121^{\circ} \mathrm{C}, 1 \mathrm{~atm}\right)$ and placed in individual wells of 24 -well culture plates. L929 mouse fibroblasts were seeded in each well at a concentration of $5 \times 10^{5}$ cells $/ \mathrm{mL}$, supplemented with $10 \%$ FBS. The incubation was performed under a $\mathrm{CO}_{2}(5 \%)$ atmosphere at $37^{\circ} \mathrm{C}$ for $24 \mathrm{~h}$. After the incubation, the substrates with DLC and NCD-DLC films as well as the positive and negative control fragments were removed from their respective wells. Only the cells that adhered to the well walls were incubated with a tetrazolium salt solution (MTT), 3-[4,5-dimethylthiozol-2-yl]-2,5-diphenyltetrazolium bromide (Sigma, St. Louis, MO, USA) at $37^{\circ} \mathrm{C}$ for $4 \mathrm{~h}$. The MTT was reduced to an insoluble formazan precipitate by mitochondrial succinic dehydrogenase of the viable cells. After removal of the medium, ethanol-dimethyl sulfoxide (DMSO) (Sigma) solution (1:1) was added to each well. After complete solubilization of the dark blue crystal of MTT formazan, the absorbance of the content of each well was measured at $570 \mathrm{~nm}$ with a 24 -well microplate reader on a spectrophotometer Spectra Count (Packard). The blank reference was taken from wells without cells, also incubated with MTT solution. The cell viability was calculated by the normalization of optical densities (OD) to the negative control (Lobo et al., 2008).

The OD were normalized by the negative control and expressed in percentage:

$$
\left[\left(\mathrm{OD}_{\text {sample }}-\mathrm{OD}_{\text {background }}\right) /\left(\mathrm{OD}_{\text {negativecontrol }}-\mathrm{OD}_{\text {background }}\right)\right]^{* 100}
$$


Data were collected from five different experiments and expressed as the average \pm the standard deviation (SD). The statistical differences were analyzed by 2 -way Anova (Graph Pad Prism $5^{\circledR}$ ). The populations from the DLC and NCD-DLC films were obtained with normal distribution and independent to each group of samples. P-values less than 0.05 were considered to indicate statistical differences (no data shown).

\section{Results and discussion}

Raman scattering spectroscopy was used to evaluate the chemical structure of the NCD-DLC films. The spectra are composed of two broad bands, centered at approximately $\sim 1400 \mathrm{~cm}^{-1}$ ( $D$ band) and $\sim 1550 \mathrm{~cm}^{-1}$ ( $G$ band). The $D$ and $G$ band peak positions were determined by subtracting a linear background and fitting a Gaussian function to the peak of the Raman spectrum. The peak position, width, and ratio of the integrated areas under $D$ and $G$ peaks were used to determine $I_{D} / I_{G}$. Figure 1 shows the spectra from DLC films containing NCD particles of different average sizes, which are vertically shifted for easy comparison. The main parameters obtained through the spectra (Fig. 1) are summarized in Tab. 1. The decrease of $I_{D} / I_{G}$ ratio, together with the shift of the $D$ band's peak position towards higher frequencies, accompanied by an increase of the bandwidth is usually interpreted as an increase of diamond-like domains (Marciano et al., 2010). Some authors reported the incorporation of metallic particles in DLC films to increase DLC corrosion resistance, but metallic particles promote the graphitization of the amorphous carbon around them due to their catalytic activity at high kinetic energy of the sputtered C species (Hayashi et al., 2001; Lee et al., 2004). In the case of NCD-DLC films, it can be deduced that the $\mathrm{sp}^{3} / \mathrm{sp}^{2}$ ratio increased with the presence of NCD particles. According to Robertson (2002), the $\mathrm{sp}^{3}$ bonding confers on DLC many of the beneficial properties of diamond itself, such as its chemical and electrochemical inertness.

The surface roughness $\left(R_{a}\right)$ was measured over an area of $229 \mu \mathrm{m}$ x $301 \mu \mathrm{m}$ and can be seen on Tab. 2. The asdeposited DLC films had roughness values around $115 \mathrm{~nm}$. The presence of bigger NCD particles (average sizes of 250 and $500 \mathrm{~nm}$ ) makes the films rougher. However, with NCD particles of $4 \mathrm{~nm}$, the roughness value slightly decreased. In this case, the NCD size $(4 \mathrm{~nm})$ was the only size less than the DLC grain size ( $10 \mathrm{~nm})$ (Bonetti et al., 2006). Thus, the NCD could occupy the nanospaces between DLC grains, reducing the roughness value.

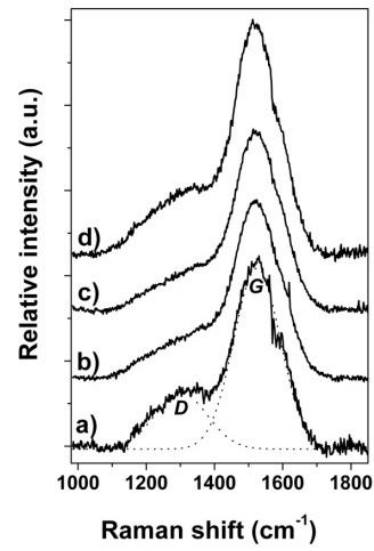

Figure 1. Raman scattering spectra from (a) DLC and NCD-DLC films containing particles of (b) $4 \mathrm{~nm}$, (c) $250 \mathrm{~nm}$, and (d) $500 \mathrm{~nm}$ average size. The spectra are vertically shifted for easy of comparison

Table 1. Gaussian fitting results of Raman spectra from DLC films with different diameters of diamond particles

\begin{tabular}{lllllll}
\hline Sample & $\begin{array}{l}\boldsymbol{D} \text { Band } \\
\text { Position } \\
\left(\mathbf{c m}^{-\mathbf{1}}\right)\end{array}$ & $\begin{array}{l}\boldsymbol{G} \text { Band } \\
\text { Position } \\
\left(\mathbf{c m}^{-\mathbf{1}}\right)\end{array}$ & $\begin{array}{l}\text { FWHM } \\
(\boldsymbol{D})\end{array}$ & $\begin{array}{l}\text { FWHM } \\
(\boldsymbol{G})\end{array}$ & $\boldsymbol{I}_{\boldsymbol{D}} / \boldsymbol{I}_{\boldsymbol{G}}$ & {$[\mathbf{H}](\boldsymbol{\%})$} \\
\hline DLC & $1301.3 \pm 1.1$ & $1522.8 \pm 1.4$ & $185.2 \pm 2.8$ & $153.6 \pm 0.4$ & $0.65 \pm .01$ & $34.1 \pm 0.3$ \\
$\begin{array}{l}\text { NCD-DLC } \\
(4 \mathrm{~nm})\end{array}$ & $1317.0 \pm 2.2$ & $1527.9 \pm 0.4$ & $243.0 \pm 4.4$ & $160.9 \pm 1.6$ & $0.50 \pm .01$ & $36.3 \pm 0.4$ \\
$\begin{array}{l}\text { NCD-DLC } \\
(250 \mathrm{~nm})\end{array}$ & $1314.9 \pm 5.1$ & $1527.1 \pm 0.8$ & $233.8 \pm 7.0$ & $159.7 \pm 4.0$ & $0.50 \pm 0.01$ & $36.6 \pm 0.5$ \\
$\begin{array}{l}\text { NCD-DLC } \\
(500 \mathrm{~nm})\end{array}$ & $1304.2 \pm 0.5$ & $1524.6 \pm 1.0$ & $222.9 \pm 2.3$ & $156.1 \pm 1.7$ & $0.57 \pm .01$ & $34.1 \pm 0.7$ \\
\hline
\end{tabular}


Table 2. Surface roughness $\left(R_{a}\right)$ of DLC and NCD-DLC films according to the NCD average sizes. The error represents the standard deviation of 5 different samples

\begin{tabular}{cc}
\hline Samples & Roughness $(\mathbf{n m})$ \\
\hline DLC & $115 \pm 8$ \\
NCD-DLC (4nm) & $92 \pm 7$ \\
NCD-DLC (250 nm) & $216 \pm 9$ \\
NCD-DLC (500 nm) & $145 \pm 5$ \\
\hline
\end{tabular}

Potentiodynamic polarization test was carried out to investigate the protective abilities of the coating. The electrochemical stability of the systems in the test solution was investigated by the open-circuit potentials (OCP). The negative OCP values for the NCD-DLC films may be caused by the penetration of the test solution (Zeng et al., 2002; Liu et al., 2008a; Wan et al., 2009). The electrochemical parameters obtained from the potentiodynamic polarization curves (Fig. 2) are given in Tab. 3. The corrosion current density $\left(i_{\text {corr }}\right)$ of NCDDLC samples was reduced by more than one order of magnitude compared to the pure DLC films. The protection efficiency (Kim et al., 2005) also indicates that NCD-DLC films offer the best protection among the uncoated samples up to $99.9 \%$ (NCD-DLC films containing particles of $500 \mathrm{~nm}$ ). The improvement in the breakdown potential values means that the extension of the passive region in the coated system and a higher polarization is necessary to trigger the onset of anodic dissolution of the system (Liu et al., 2008a; Dorner-Reisel et al., 2004). In general, the samples in the corrosion behavior with lower current density and higher potential indicate better corrosion resistance (Sui et al., 2009). An improvement in the corrosion resistance of DLC films due to the presence of NCD particles is evidenced by a shift of the polarization curve towards the region of lower current density and higher potential.

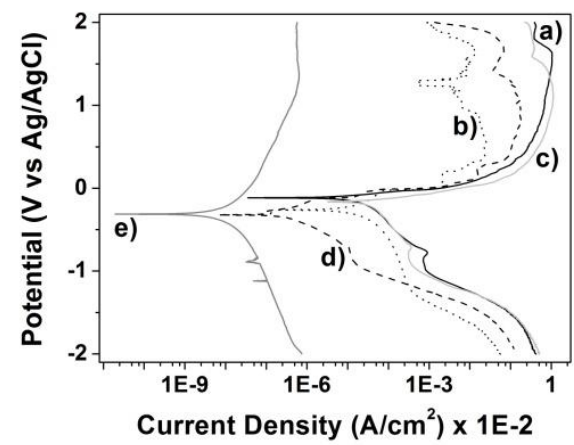

Figure 2. Potentiodynamic polarization curves of (a) stainless steel, (b) DLC, and NCD-DLC films with(c) $4 \mathrm{~nm}$, (d) $250 \mathrm{~nm}$, and (e) $500 \mathrm{~nm}$ diameter particles

Table 3. Electrochemical parameters obtained from potentiodynamic polarization curves

\begin{tabular}{cccc}
\hline Samples & $\boldsymbol{E}_{\text {corr }}(\mathbf{m V})$ & $\boldsymbol{i}_{\text {corr }}\left(\mathbf{n A} / \mathbf{c m}^{2}\right)$ & Protectionefficiency (\%) \\
\hline Stainless steel & -0.123 & 0.3589 & - \\
DLC & -0.256 & 3.0450 & - \\
NCD-DLC (4nm) & -0.169 & 30.715 & 80.4 \\
NCD-DLC (250 nm) & -0.321 & 0.0703 & 99.9 \\
NCD-DLC (500 nm) & -0.309 & 0.0002 & - \\
\hline
\end{tabular}

The difference in corrosion behavior of DLC films is assigned to the difference in microstructure of these films (Liu et al., 2008b). Generally, the higher $\mathrm{sp}^{3} / \mathrm{sp}^{2}$ ratio is the higher electrochemical corrosion resistance (Ferrari et al., 2000; Sui et al., 2009).

The Nyquist plots determined by the EIS technique (Fig. 3) show the different corrosion behavior of the samples after immersion in $\mathrm{NaCl}$. NCD-DLC films have superior impedance compared to the DLC and the substrate. The mechanism for improving the corrosion resistance is related to the reduced electron conductivity of NCD-DLC films compared to stainless steel and the pure DLC (Sui et al., 2007). The low electrical conductivity of the NCD-DLC films reduces the electron transport and exchange of electrical charges on the sample surface, which is necessary for electrochemical corrosion (Annett et al., 2004; Sui et al., 2007). 


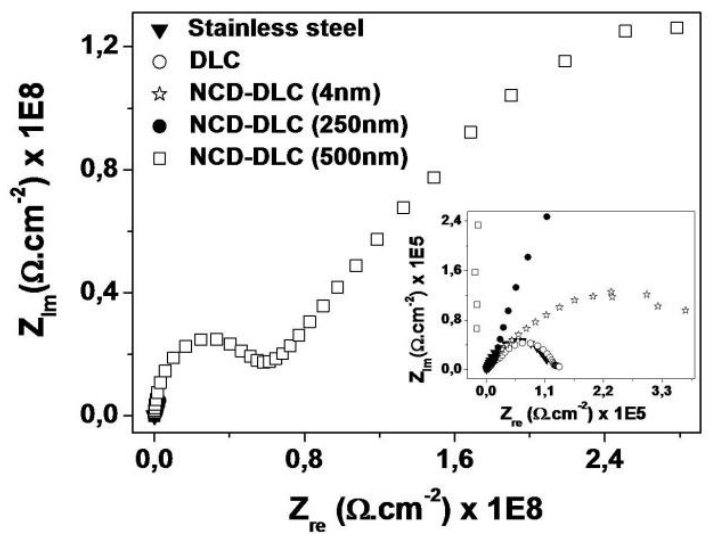

Figure 3. Nyquist plot of stainless steel, DLC, and NCD-DLC films

The cell viability is positively correlated with the degree of MTT reduction (Mosmann et al., 1983; Flahaut et al., 2006; Hussain et al., 2005). Figure 4 shows the cell viability found for DLC and NCD-DLC films, compared to the negative and positive control. The positive control has very low cell viability, characterizing cell death (no data shown). A high index of cell viability is shown for DLC and NCD-DLC films. Compared to the positive control, the DLC and NCD-DLC films are evidently non-toxic.

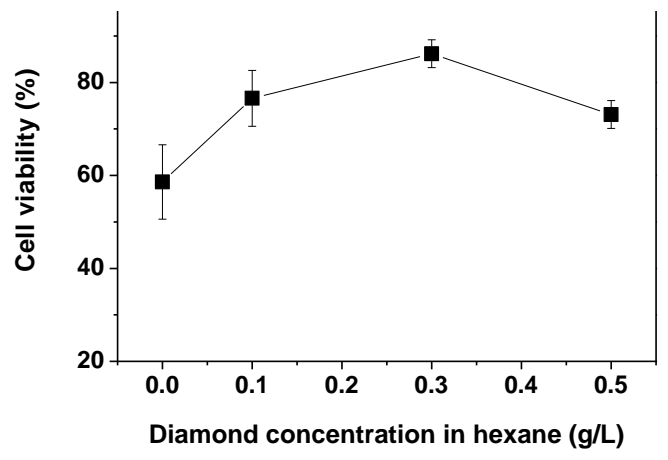

Figure 4. L929 mouse fibroblasts viability curve measured by MTT assay

Several studies have been performed on the biocompatibility of DLC films that contain different kind of elements or/and nanoparticles such as fluorine, nitrogen, silicon, silver, zirconium dioxide $\left(\mathrm{ZrO}_{2}\right)$, chromium, and titanium (Ali et al., 2006; Bharathy et al., 2010; Bendavid et al., 2007, 2010; Randeniya et al., 2009, 2010a, 2010b). However, this is the first time that NCD-DLC films have been used.

Cell viability studies prove that DLC films do not inhibit cell growth, but the introduction of such elements in the films cause a change in this behavior, sometimes increasing or decreasing the cell viability (Ali et al., 2006; Bharathy et al., 2010; Bendavid et al., 2007, 2010; Randeniya et al., 2009, 2010a, 2010b). This leads to a discussion about the influence of these elements, including their concentration, topography, and surface energy.

Figure 4 shows an increase in cell viability from 58.6 to $73.1 \%$ with the addition of only $0.1 \%$ of crystalline diamond nanoparticles. Similar studies have shown this increase in cell viability with greater concentrations of elements such as $6.8 \%$ fluorine (Bendavid et al., 2010), $4 \% \mathrm{ZrO}_{2}$ (Randeniya et al., 2010), 21\% silicon (Bendavid et al., 2007; Randeniya et al., 2009), 5\% chromium (Ali et al., 2006), 1.1\% titanium dioxide $\left(\mathrm{TiO}_{2}\right.$ ) (Randeniya et al., 2010). The exact reason for this increase is not well elucidated; however, a hypothesis is the hydrophilicity and the increase of the surface roughness with the addition of such elements (Ali et al., 2006; Michiardi et al., 2007). Furthermore, Chai et al. (2008) indicated that a slight hydrophobicity of the DLC films is favorable to the absorption of hydrophobic adhesion proteins in the case of Si-DLC.

Our study also shows a peak in cell viability with $0.3 \%$ NCD particles (Fig. 4). This result agrees with other studies that have shown a maximum peak of cell viability: $4 \% \mathrm{ZrO}_{2}$ (Randeniya et al., 2010), 5\% chromium (Ali et al., 2006), and $3 \% \mathrm{TiO}_{2}$ (Randeniya et al., 2010). At $0.5 \%$ NCD particles, our study found a slight decrease in cell viability (Fig. 4). This decrease has also been observed in other studies using elements such as $21 \%$ fluorine 
(Bendavid et al., 2010), 21\% silicon (Bendavid et al., 2007; Randeniya et al., 2009), 10\% chromium (Ali et al., 2006), and $13 \% \mathrm{TiO}_{2}$ (Randeniya et al., 2010). Among the factors that could explain this decrease, Bharathyet al. (2010) said that the release of ions could form a barrier to cell development. However, this is not a rule for every element. DLC microstructure can also influence this behavior due to its element density and topographic (Mossman et al., 1983; Randeniya et al., 2010), because cellular adhesion is generally dependent on time, adhesive forces at the cell/material interface, and surface topography.

\section{Conclusion}

This manuscript reports the production and characterization of crystalline diamond nanoparticle-incorporated into DLC films for biomedical applications, which includes the evaluation of cellular behavior when films are in direct contact with this new biomaterial. NCD particles increased the structural diamond-like domains and surface roughness. The presence of bigger nanoparticles, especially $500 \mathrm{~nm}$, improved DLC and stainless steel electrochemical corrosion resistance. NCD-DLC films show superior electrochemical impedance and low electrical conductivity, becoming a potential candidate for an anti-corrosion material in biomedical applications. The DLC and NCD-DLC films proved to be non-cytotoxic. The NCD particles increased DLC cell viability, which also maximizes the potential use of NCD-DLC films in biomedical applications. It is clear that this is only the first step in this area. However, DLC films have a huge range of applications. In the way that it is demonstrated in this manuscript, the NCD-incorporated DLC films can modify the DLC structure, thereby increasing their range of applications in new scientific and technological applications. In conclusion, Space Research is very important not only for the space area itself but, primarily, for providing direct and immediate contributions in areas related to health, petroleum, corrosion, mechanics, etc.

\section{Acknowledgements}

This study was supported by Conselho Nacional de Desenvolvimento Científico e Tecnológico (CNPq) and Fundação de Amparo à Pesquisa do Estado de São Paulo (FAPESP).

\section{References}

Ali, N.; Kousar, Y.; Okpalugo, T.I.; Singh, V.; Pease, M.; Ogwu, A.A.; Gracio, J.; Titus, E.; Meletis, E.I.; Jackson, M.J. Thin Solid Films 515 (2006) 59.

Annett, D.R.; Schurer, C.; Irmer,G.; Muller, E. Surface and Coatings Technology177-178 (2004) 830.

Bendavid, A.; Martin, P.J.; Comte, C.; Preston, E.W.; Haq, A.J.; Magdon-Ismail, F.S.; Singh, R.K. Diamond and Related Materials 16 (2007) 1616.

Bendavid, A.; Martin, P.J.; Randeniya, L.; Amin, M.S.; Rohanizadeh, R. Diamond and Related Materials 19 (2010) 1466.

Bharathy, V.P.; Nataraj, D.; Paul, K.; Chu, W.; Yang, Q.; Kiran, M.S.R.N.; Silvestre-Albero, J.; Mangalaraj, D. Applied Surface Science 257 (2010) 143.

Bonetti, L.F.; Capote, G.; Santos, L.V.; Corat, E.J.; Trava-Airoldi, V.J. Thin Solid Films, 515 (2006) 375.

Casiraghi, C.; Ferrari, A.C.; Robertson, J. Physical Review B 72 (2005a) 385.

Casiraghi, C.; Piazza, F.; Ferrari, A.C.; Grambole, D.; Robertson, J. Diamond and Related Materials 14 (2005b) 1098.

Chai, F.; Mathis, N.; Blanchemain, N.; Meunier, C.; Hartmut-Hildebrand, F. Acta Biomaterialia 4 (2008) 1369.

Donnet, C.; Fontaine, J.; Le Mogne, T.; Belin, M.; Héau, C.; Terrat, J.P.; Vaux, F.; Pont, G. Surface and Coatings Technology 120 (1999) 548.

Dorner-Reisel, A.; Schurer, C.; Irmer, G.; Muller, E. Surface and Coatings Technology 177-178 (2004) 830.

Feng, H.P.; Hsu, C.H.; Lu, J.K.; Shy, Y.H. Materials Science Engenieering A 347 (2003) 123.

Ferrari, A.C.; Robertson, J. Physical Review B 61 (2000) 14095.

Films 347 (1999) 60.

Films 494 (2006) 84.

Flahaut, E.; Durrieu, M.C.; Remy-Zolghadri, M.; Bareille, R.; Baquey, Ch. Journal of Materials Science 41 (2006) 2411.

Hayashi, Y.; Krishna, K.M.; Ebisu, H.; Soga, T.; Umeno, M.; Jimbo, T. Diamond and Related Materials10 (2001) 1002.

Hsieh, W.J.; Shih, P.S.; Lin, J.H.; Lin, C.C.; Chen, U.S.; Huang, S.C.; Chang, Y.S.; Shih, H.C. Thin Solid Films 469-470 (2004) 120.

Hussain, S.; Roy, R.K.; Pal, A.K. Materials Chemical Physics 99 (2006) 375.

Hussain, S.M.; Hess, K.L.; Gearhart, J.M.; Geiss, K.T.; Schlager, J.J. Toxicology In Vitro 19 (2005) 975.

Kim, H.G.; Ahn, S.H.; Kim, J.G.; Park, S.J.; Lee, K.R. Diamond and Related Materials 14 (2005)35.

Lee, C.S.; Kim, T.Y.; Lee, K.R.; Yoon, K.H. Thin Solid Films 447-448 (2004) 169.

Lian, G.D.; Dickey, E.C.; Ueno, M.; Sunkara, M.K. Microscopy and Microanalysis 8 (2002) 1146.

Liu, C.; Xu, M.; Zhang, W.; Pu, S.; Chu, P.K. Diamond Relat.Mater.17 (2008a) 1738. 
Liu, E.; Kwek, H.W. Thin Solid Films 516 (2008b) 5201.

Lobo, A.O.; Antunes, E.F.; Machado, A.H.A.; Pacheco-Soares, C.; Trava-Airoldi, V.J.; Corat, E.J. Materials Science Engineering C 28 (2008) 264.

Marciano, F.R.; Almeida, E.C.; Lima-Oliveira, D.A.; Corat, E.J.; Trava-Airoldi, V.J. Surface and Coatings Technology 204 (2010) 2600.

Marciano, F.R.; Bonetti, L.F.; Da-Silva, N.S.; Corat, E.J.; Trava-Airoldi, V.J. Synthetic Metals 159 (2009) 2167.

Matsumoto, Y.; Kurimoto, J.; Shimizu, T.; Sato, E. Journal of Electrochemical Society 108 (1981)1040.

Michiardi, A.; Aparicio, C.; Ratner, B.D.; Planell, J.A.; Gil, J. Biomateriais, 28 (2007) 586.

Mosmann, T. Journal of Immunology Methods 65(1983) 55.

Ohno, T.; Haga, D.; Fujihara, K.; Kaiazaki, K.; Matsumura, M. Journal of Physcal Chemistry B 101(1997) 6415.

Randeniya, L.K.; Bendavid, A.; Martin, P.J. Amin, S. Preston, E.W. Magdon-Ismail, F.S.; Coe, S. Acta Biomaterials 5 (2009) 1791.

Randeniya, L.K.; Bendavid, A.; Martin, P.J.; Amin, S.; Rohanizadeh, R.; Tang, F.; Cairney, J.M. Diamond and Related Materials 19 (2010) 329.

Randeniya, L.K.; Bendavid, A.; Martin, P.J.; Cairney, J.; Sullivan, A.; Webster, S. Proust, G.; Tang, F.; Rohanizadeh, R. Acta Biomaterials 6 (2010a) 4154.

Robertson, J. Materials Science Engineering R 37 (2002) 129.

Sakudo, N.; Ikenaga, N.; Yasui, H.; Awazu, K. Thin Solid Films 516 (2008) 4483.

Schiffmann, K.I. Surface and Coatings Technology 177-178 (2004) 453.

Schiffmann, K.I.; Fryda, M.; Goerigk, G.; Lauer, R.; Hinze, P.; Bulack, A. Thin Solid

Schmid, G. Chemical Review 92 (1992) 1709.

Shirakura, A.; Nakaya, M.; Koga, Y.; Kodama, H.; Hasebe, T.; Suzuki, T. Thin Solid

Sui, J.H.; Gao, Z.Y.; Cai, W.; Zhang, Z.G. Materials Science Engineering A 452-453 (2007) 518.

Sui, J.H.; Zhang, Z.G.; Cai, W. Nuclear Instruments and Methods B 267 (2009) 2475.

Suzuki, T.; Kodama, H. Diamond and Related Materials 18 (2009) 990.

Takahara, Y.; Kondo, J.N.; Takata, T.; Lu, D.L.; Domen, K. Chemical Materials 13 (2001)1194.

Tanaka, T.; Takenaka, S.; Funabiki, T.; Yoshida, S. Journal Chemical Society Faraday Transactions 92 (1996) 1975.

Tsai, P.C.; Hwang, Y.F.; Chiang, J.Y.; Chen, W.J. Surface and Coatings Technology 202 (2008) 5350.

Wan, S.; Wang, L.; Xue, Q. Electrochemistry Communications 11 (2009) 99.

Wang, Q.F.; Yu, H.J.; Zhong, L.; Liu, J.Q.; Sun, J.Q.; Shen, J.C. Chemical Materials 18 (2006) 1988.

Wang, Z.P.; Yousefi, H.R.; Nishino, Y.; Ito, H.; Masugata, K. Physics Letters A 373 (2009) 4169.

Zarrabian, M.; Fourches-Coulon, N.; Turban, G.; Marhic, C.; Lancin, M. Applied Physics Letter 70 (1997) 2535.

Zeng, A.; Liu, E.; Annergren, I.F.; Tan, S.N.; Zhang, S.; Gao, J. Diamond and Related Materials 11 (2002) 160. 